\title{
Temporal perception in obese and normal-weight subjects: A test of the stimulus-binding hypothesis*
}

\author{
ROBERT M. STUTZ, JOEL S. WARM \\ and WILLIAM A. WOODS \\ University of Cincinnati, Cincinnati, Ohio 45221
}

Obese and normal-weight Ss judged the duration of a $1,000-\mathrm{Hz}$ tone at four standard intervals, $3,8,13$, and $18 \mathrm{sec}$, using the method of production. Consistent with the prediction from Schachter's (1971) stimulus-binding hypothesis, response accuracy, in terms of absolute error, was poorer for the obese than for the normals. This effect was notable predominantly at the longer stimulus durations. In general, the magnitude of absolute errors decreased over trials, even though explicit feedback regarding performance efficiency was not provided.

Schachter and his associates have compared the eating behavior of obese and normal-weight Ss in a variety of experimental and field situations (Schachter, 1968, 1971). They have reported that the perceptual salience of food cues, such as taste, and social and situational stimuli associated with eating are more likely to affect the consummatory activity of the obese than of normals. Schachter (1971) has accounted for these findings in terms of the stimulus-binding hypothesis which maintains that, relative to normals, obese individuals are more sensitive to external than to internal cues and consequently, their eating behavior is more externally than internally controlled. Moreover, Schachter has suggested that such stimulus binding is not limited to eating situations and that the obese are generally more responsive to external stimuli than are individuals of normal weight. Support for this position comes from the fact that the performance of obese Ss in proofreading and choice reaction time tasks is more disrupted by distracting, irrelevant stimuli than is that of normal controls (Rodin, 1973).

The perception of stimulus duration is still another area to which Schachter's hypothesis may be extended. Judgments of time are often based upon a paucity of external cues (Doob, 1971; Falk \& Bindra, 1954; Warm \& McCray, 1969), and evidence is accumulating from a variety of sources that internal physiological cues play a crucial role in temporal perception (see Doob, 1971). Consequently, the stimulus-binding hypothesis leads to the prediction that obese individuals will be more inaccurate than normals in judging stimulus duration. The present investigation was designed to test this prediction.

*Supported in part by the National Science Foundation through Research Grant NSF GB-27654 and by the Institute of Space Sciences of the University of Cincinnati through National Aeronautics and Space Administration Grant NGL-36-004-014. The authors are indebted to Paul Karoly for his helpful comments.

\section{METHOD \\ Subjects}

Forty students from the University of Cincinnati served as Ss. None had previously participated in a study of temporal perception. The obese group consisted of 11 men and 9 women between the ages of 18 and 24 years (mean age: 20 years). They had a mean height of $5 \mathrm{ft} 7 \mathrm{in}$. (range: $5 \mathrm{ft} 4$ in. to $6 \mathrm{ft} 2 \mathrm{in}$.) and an average weight of $194 \mathrm{lb}$ (range: $145-245 \mathrm{lb}$ ). A criterion of $15 \%$ overweight was adopted for inclusion in the obese group (Schachter \& Gross, 1968). Based upon the Metropolitan Life Insurance Co. (1959) norms for average weight, obese Ss ranged from $16 \%$ to $61 \%$ overweight, with a mean of $30 \%$ overweight. The normal group was identical to the obese group in terms of sexual composition and average height (the heights of Ss in this group varied from $5 \mathrm{ft} 2$ in. to $6 \mathrm{ft} 5 \mathrm{in}$.), and was similar to the obese group in terms of average age (mean age: 19 years; range: $18-25$ years). The normals varied in weight from 110 to $196 \mathrm{lb}$, with a mean of $144 \mathrm{lb}$. On the basis of the Metropolitan Life Insurance Co. norms, the Ss in this group were, on the average, $1.2 \%$ underweight (range: $24 \%$ underweight to $8 \%$ overweight; distribution: negatively skewed).

\section{Apparatus and Procedure}

All Ss judged the duration of a $1,000-\mathrm{Hz}$ tone at four standard intervals. 3. 8, 13, and $18 \mathrm{sec}$, by the method of production (Bindra \& Waksberg, 1956). The acoustic signal was the output of a Hewlett-Packard audio oscillator and was presented to $S$ binaurally via headphones at an intensity of $78 \mathrm{~dB}$ SPL. The sequence of occurrence of the four standard intervals was block randomized for each S. Five blocks of 20 trials were used; each interval appeared five times in random order within each block. A $2-\mathrm{sec}$ intertrial interval was maintained within blocks, and Ss were permitted a 2 -min rest between blocks.

Each S was seated alone in an Industrial Acoustics sound chamber. Voice communication with $\mathrm{E}$ was maintained by an intercom. At the start of a trial, $\mathrm{E}$ announced the interval to be produced and activated the audio oscillator. The $\mathrm{S}$ extinguished the tone when he felt that it had reached the appropriate duration by pressing a hand-held microswitch. Responses were recorded to the nearest $1 / 100 \mathrm{sec}$ by means of a Standard Electric Model S-1 timer, which was enabled automatically with the onset of the tone and terminated by S's response. The Ss were asked not to count or tap in making their judgments, and timepieces were removed at the start of the session. Feedback regarding performance efficiency was not provided.

\section{RESULTS}

For each S, median absolute errors (difference between a standard interval and the response to that interval disregarding algebraic sign) were computed for the four stimulus durations within each block of trials. Means of median absolute errors for obese and normal Ss are plotted in Fig. 1 as a function of blocks. The data for the different stimulus durations are presented separately in each panel.

An analysis of variance of the data indicated that overall error magnitude increased with increments in stimulus duration $(\mathrm{F}=117.97, \mathrm{df}=3 / 114, \mathrm{p}<.001)$. The main effect for groups was not significant $(F=2.34$, $\mathrm{df}=1 / 38, \mathrm{p}>.05)$. However, a significant Groups by 


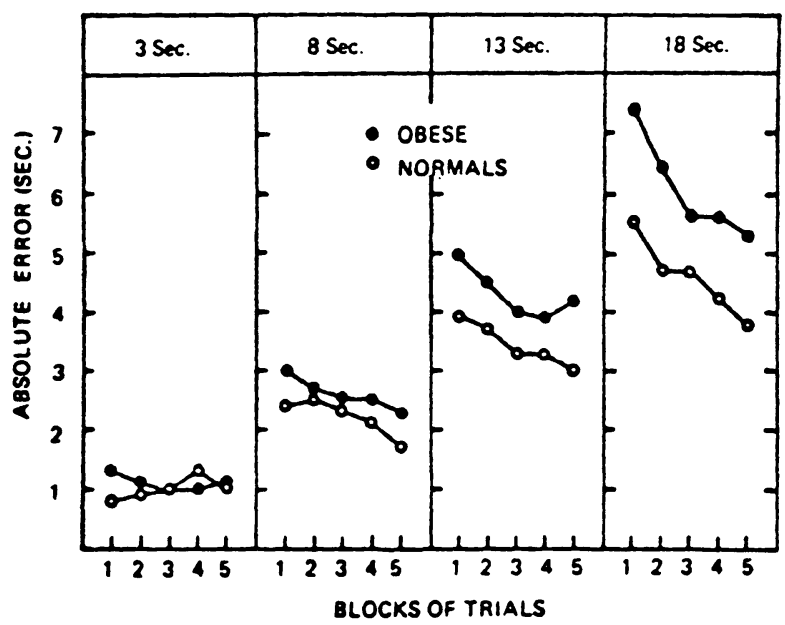

Fig. 1. Means of median absolute errors as a function of blocks of trials for obese and normal-weight groups. Data for the four standard intervals are plotted separately in each panel.

Intervals interaction $(F=3.09, \mathrm{df}=3 / 114, \mathrm{p}<.05)$ indicated that responses by the obese were associated with a greater degree of error than those of the normals at the longer relative to the shorter intervals. For both groups of Ss, the magnitude of absolute errors decreased significantly with trials $(F=3.30, d f=4 / 152, p<.025)$, and this effect was also more notable at the longer durations $(F=3.01, \mathrm{df}=12 / 456, \mathrm{p}<.005)$. All other interactions lacked significance $\left(\mathrm{F}<1\right.$ in each case) ${ }^{1}$

\section{DISCUSSION}

The results of this investigation extend the applicability of Schachter's (1971) stimulus-binding hypothesis to the area of temporal perception. Consistent with the prediction derived from this position, obese individuals were found to be less accurate than those of normal weight in judging stimulus duration.

As indicated by the significant Groups by Intervals interaction, differences in response accuracy between the obese and the normals were observed predominantly at the longer intervals. Such a result is also generally consistent with expectations from Schachter's hypothesis. In the present study, as in other investigations (Robinson, 1963; Underwood, 1966; Woodrow, 1951), response accuracy was inversely related to stimulus duration. It therefore seems reasonable to assume that both internal and external cues to signal duration became more ephemeral with increments in the intervals to be judged. Since the stimulus-binding notion maintains that the performance of the obese is dependent primarily upon external cue prominence, the interaction between groups and intervals observed here fits easily within the implications of Schachter's hypothesis.

One of Schachter's most provocative experiments was one in which the food intake of obese and normals was observed when laboratory clocks were modified so as to read earlier or later than actual elapsed time (Schachter \& Gross, 1968). The consummatory activity of the obese Ss was more influenced by apparent clock time than was that of the normals. The results of the present study suggest that this effect may have been potentiated not only by the relative insensitivity of the obese to internal hunger cues as Schachter maintains, but also by their relative inability to make accurate judgments of elapsed time.
An important feature in the present data is the finding that response accuracy increased over trials in the absence of explicit feedback regarding performance efficiency. Previous studies using the method of production have demonstrated that the absolute magnitude of responses to a constant interval increases over a series of trials (Falk \& Bindra, 1954; Robinson, 1963; Warm, Foulke, \& Loeb, 1966). The present results imply that when absolute error is used as the index of performance, this serial effect may reflect improvement in response accuracy with practice. Among other things, such improvement could result from (a) increments in sensitivity to subtle time-relevant cues, or (b) changes in S's decision criterion as to when to terminate his response (Von Sturmer, 1968), or both. The degree to which the serial effect is mediated by such factors remains to be determined by future research.

\section{REFERENCES}

Bindra, D., \& Waksberg, H. Methods and terminology in studies of time estimation. Psychological Bulletin, 1956, 53, 155-159. Doob, L. W. Patterning of time. New Haven: Yale University Press, 1971.

Falk. J. L., \& Bindra, D. Judgment of time as a function of serial position and stress. Journal of Experimental Psychology, 1954, 47, 279-282.

Metropolitan Life Insurance Company. New weight standards for men and women. Statistical Bulletin, 1959, 40, 1-4.

Robinson, $E$. The effect of degree of knowledge of results on time estimation. Psychological Record, 1963, 13, 355-360.

Rodin, J. Effects of distraction on performance of obese and normal subjects. Journal of Comparative \& Physiological Psychology, 1973, 83, 68-75.

Schachter, S. Obesity and eating. Science, 1968, 161, 751-756

Schachter, S. Obesity and eating. Scts about obese humans and rats. American Psychologist, 1971, 26, 129-144.

Schachter, S., \& Gross, L. Manipulated time and eating behavior. Journal of Personality \& Social Psychology, 1968, 10, 98-106 Underwood, B. J. Experimental psychology. (2nd ed.) New York: Appleton-Century-Crofts, 1966.

Von Sturmer, G Time perception, vigilance and decision theory. Perception \& Psychophysics, 1968, 3, 197-200.

Warm, J. S., Foulke, E., \& Loeb, M. The influence of stimulus-modality and duration on changes in temporal judgments over trials. American Journal of Psychology. 1966, 79, 628-631.

Warm, J S \& McCray, R. E. Influence of word frequency and length on the apparent duration of tachistoscopic presentations. Journal of Experimental Psychology, 1969, 79 , 56-58.

Woodrow, H. Time perception. In S. S. Stevens (Ed.), Handbook of experimental psychology. New York: Wiley, 1951. Pp. 1224-1236.

\section{NOTE}

1. Median production magnitudes were also computed for each $S$ for the four stimulus durations within each block of each $S$ for the four stimulus durations within each block of
trials. An analysis of variance of these data indicated that production magnitude was directly related to stimulus duration $(F=328.36, \mathrm{df}=3 / 114, \mathrm{p}<.001)$. In general, elapsed time tended to be overestimated, i.e., production responses were shorter than the standard at all intervals. The magnitude of productions increased significantly over blocks of trials (F = 13.72, df $=4 / 152$, $p<.001$ ), and this effect was more notable at the longer relative to the shorter durations $(F=9.00, \mathrm{df}=$ $12 / 456, p<.001)$. No significant differences were found between groups $(F<1)$ and all interactions involving groups also lacked significance ( $\mathrm{p}>.05$ in each case). Such results indicate that the obese Ss did not systematically overestimate or underestimate time relative to the normals. Apparently, the difference between obese and normal individuals in the temporal production task resides predominantly in the accuracy of responding.

(Received for publication September 28, 1973.) 